\title{
UM ESTUDO DE CASO SOBRE A IMPORTÂNCIA DAS VARIÁVEIS “GÊNERO” E “IDADE” NA APRENDIZAGEM DE L2 NO ENSINO MÉDIO
}

\section{A STUDY OF CASE ABOUT THE RELEVANCE OF GENDER AND AGE TO L2 LEARNING IN HIGH SCHOOL}

\author{
Ana Mirtiz Veronezi"
}

Resumo: O objetivo da presente pesquisa é discutir a possível relação entre idade e gênero na aquisição de vocabulário em L2, tendo como campo de pesquisa duas turmas do primeiro ano do Ensino Médio de uma escola pública regular da região de Curitiba, Paraná, Brasil. Como parte da pesquisa, um dos grupos recebeu complementação lexical e o outro foi acompanhado como grupo de controle para que os dados coletados, relativos à aprendizagem lexical, pudessem ser comparados de forma intergrupal e intragrupal entre os participantes dos dois grupos. Todavia, os dados coletados sinalizaram para a necessidade de mais estudos, com maior número de participantes, a respeito do impacto dos fatores "idade" e "gênero" para a aprendizagem de L2.

Palavras-chave: Vocabulário; Gênero; Idade.

\begin{abstract}
Aвstract: The aim of this research is to discuss a possible correlation between students' age and gender through the process of vocabulary acquisition in L2, according to the data collected from two groups of fresh students from a High School located in Curitiba, Paraná, Brazil. One of those groups went on a process of lexical implementation, while the other one was followed up as a control group to compare the data related to lexical learning among the individuals in each group, as well as establishing a comparison between groups. However, data signaled to the need of further studies, with a larger number of participants, on the impact of age and gender to L2 learning.
\end{abstract}

KEYworDs: Vocabulary; Gender; Age.

\footnotetext{
"Mestre em Linguística Aplicada pela Universidade Federal do Paraná (UFPR) e professora na Secretaria de Estado da Educação do Paraná (SEED-PR). E-mail: aneveronezi@hotmail.com.
} 


\section{INTRODUÇÃo}

Com a perspectiva de estudar o processo de aquisição de vocabulário em língua estrangeira (L2) no repertório de leitura dos sujeitos investigados, esta pesquisa de campo conduzida ao longo de três meses - de abril a junho de 2018 - foi parte de uma dissertação ${ }^{1}$ sobre a importância de diferentes variáveis para a aquisição de léxico em L2.

Para a pesquisa realizada, os dados coletados foram comparados e contrastados tanto entre dois grupos de sujeitos participantes, como entre os sujeitos presentes em cada grupo da pesquisa conduzida. Dessa forma, para essa coleta, houve uma abordagem tanto quantitativa quanto qualitativa, uma vez que os dados obtidos foram separados de acordo com o percentual de acertos dos sujeitos e grupos pesquisados, além de ser analisado o progresso dos participantes em uma breve análise intergrupos e intersujeitos.

Assim sendo, o objetivo da pesquisa realizada foi comparar o progresso relativo à aquisição de léxico em L2, mais especificamente em língua inglesa. Para a verificação desse desenvolvimento lexical em L2, o escopo da presente pesquisa foi a testagem da eficácia do processo de implementação de vocabulário em sala de aula com o objetivo de facilitar o trabalho didático a ser desenvolvido nos três anos subsequentes do Ensino Médio regular, nível voltado principalmente à compreensão de textos escritos, em uma pesquisa com dados oriundos de alunos e alunas de duas turmas do primeiro ano do Ensino Médio regular, no período da pesquisa, tanto entre as turmas acompanhadas - análise intersujeitos - quanto entre os alunos de cada uma dessas turmas - análise intrassujeitos - ao logo de três fases de testes na pesquisa (descritas mais adiante neste artigo).

A pesquisa realizada teve como pressupostos que, no trabalho com língua estrangeira no Ensino Médio, o professor verifica alguns problemas, no contexto brasileiro, que afetam o desenvolvimento do aluno em L2:

a. Alunos com pouco conhecimento sobre o léxico da língua-alvo, apesar de quase todos terem tido a língua inglesa como língua estrangeira, como previsto pela grade curricular da etapa final do Ensino Fundamental II, muitas vezes cursando a disciplina de língua estrangeira apenas por esta ser obrigatória. Fato considerado preocupante por Flege (2019), que menciona a atitude positiva com relação ao aprendizado de línguas como um fator importante, muito embora o autor reconheça não ser possível mensurá-la adequadamente em testes;

b. Pouco tempo de contato formal com a L2 - cerca de 80 horas-aula anuais - para que o aluno desenvolva competências básicas de proficiência para o Ensino Médio e requeridas por exames acadêmicos, tais como o Exame Nacional para o Ensino médio (ENEM) ou sistemas de acesso a universidades;

${ }^{1}$ Dissertação realizada sob a orientação do professor doutor Ronald Barry Martinez. 
c. Material didático não compatível com o nível de proficiência real dos alunos ingressos no Ensino Médio regular;

d. Alunos com baixo interesse em estudar L2 em escola regular, o que pode ter influenciado nos dados coletados nesta pesquisa.

Desse modo, este estudo contou com aprendizes reais, diferentemente do público de outros estudos, pois, conforme bem observado por Flege (2019), os participantes em pesquisas linguísticas são geralmente pessoas com bom grau de escolarização na língua-alvo que fazem parte de uma comunidade universitária ou pertencem aos "seus arredores". Além disso, esse autor defende que os participantes tenham seus desempenhos avaliados com base no aprendizado que estão recebendo, ao invés de serem considerados seus conhecimentos prévios da língua (FLEGE, 2019), o que, de fato, pode interferir nos resultados das pesquisas, além de possibilitar aprimoramentos no ensino-aprendizagem com aprendizes reais.

Com relação à língua estrangeira adotada na escola regular no Brasil, o currículo do Ensino Médio restringe as opções dos alunos, pois contempla basicamente a língua inglesa como L2. No Paraná, o inglês é a L2 mais comum e tende a ser a única língua estudada oficialmente em sala de aula após a implantação da Base Nacional Comum Curricular (BRASIL, 2018) na grade curricular de ensino. Assim, a possibilidade de contato com outras línguas tornou-se ainda mais escassa, pois a oferta de outros idiomas, tais como francês, espanhol, italiano e alemão, restringe-se a algumas instituições básicas públicas muito específicas, pois são ofertados apenas por centros de línguas estrangeiras modernas (CELEMs), presentes em algumas escolas estaduais, cujas aulas são no período do contraturno para os estudantes regulares, com ofertas das (escassas) vagas também para membros da comunidade.

Desse modo, com poucas pesquisas relacionadas à aprendizagem de L2 por alunos de escolas regulares do ensino básico e com a obrigatoriedade de apenas uma língua estrangeira, aliadas à descrença do público-alvo em relação à efetividade do aprendizado de L2 em sala de aula ${ }^{2}$ na escola regular, esta pesquisa de campo teve por objetivo testar a validade do processo de implementação lexical em sala de aula como forma de aquisição de vocabulário por alunos do primeiro ano do Ensino Médio, os quais geralmente apresentam pouca ou, aparentemente, base alguma na língua estrangeira alvo.

Assim, neste artigo, devido a uma delimitação de conteúdo, será apresentada parte da pesquisa citada acima sobre a aquisição de vocabulário por alunos ingressos no Ensino Médio, de uma escola da região de Curitiba, com um recorte que contempla duas variáveis pesquisadas como possíveis causas para a (não) aprendizagem de L2:

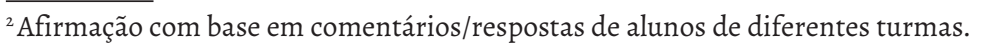


- Idade e aprendizagem;

- Gênero ${ }^{3}$ (masculino ou feminino) e aprendizagem.

Tais variáveis foram selecionadas por ser tanto socialmente quanto culturalmente aceito que os meninos (gênero masculino) são mais imaturos do que as meninas (gênero feminino) durante o período escolar e também em relação a tarefas sociais (DAL'IGNA, 2007).

Para a coleta e posterior análise dos dados, dois grupos de alunos foram acompanhados: um grupo de intervenção (denominado também como G - I, neste estudo) e outro denominado grupo de controle $(G-C)$, pois, aliado ao conteúdo didático contendo o vocabulário-teste, o grupo de intervenção recebeu o processo de implementação lexical, sob instrução tanto explícita ${ }^{4}$ quanto implícita, enquanto o grupo de controle recebeu o mesmo conteúdo didático que o grupo de intervenção, mas não recebeu a mesma implementação lexical com relação ao vocabulário sob testagem.

Após o período da pesquisa, os dados foram compilados e comparados para verificar se indicavam maior retenção lexical e, assim, maior reconhecimento de tais itens por parte do $\mathrm{G}-\mathrm{I}$, após repetidas exposições a tais itens (cerca de dez exposições), de modo que os alunos pesquisados conseguissem recuperá-los durante a realização de atividades que requeressem seu uso ${ }^{5}$ na tentativa de verificar a retenção lexical oriunda desse processo de implementação lexical (SCHMITT, 2008).

\section{Processo de INTERVEnÇão PaRA aQUiSição de VocabuláRIo}

Com o intuito de corroborar ou refutar a importância de atividades de implementação lexical para o desenvolvimento do vocabulário em L2 entre alunos do primeiro ano do Ensino Médio, foram utilizadas como referenciais teórico-metodológicos duas pesquisas de autores consagrados na área de aquisição de vocabulário.

A primeira pesquisa (MCLAUGHLIN; AUGUST; SNOW, 2000) apresenta um estudo longitudinal em que os pesquisadores acompanharam tanto alunos nativos como alunos não nativos, do quarto ano e do quinto ano do Ensino Fundamental de algumas escolas estadunidenses participantes, cujos familiares são hispânicos e não falantes de inglês. Parte desses

${ }^{3} \mathrm{O}$ termo "gênero", nesta pesquisa, faz referência ao sexo biológico do indivíduo, uma vez que, entre os(as) informantes, todos(as) se identificaram no início da coleta de dados com o gênero correspondente ao sexo biológico, i.e., masculino/ masculino e feminino/feminino.

${ }^{4} \mathrm{~A}$ instrução explícita é utilizada para enfatizar determinado item, pois há a explicação metalinguística sobre tal item. Para aquisição de vocabulário, há autores que defendem ora a instrução explícita, ora a implícita, ou ainda há os autores que ressaltam a importância de ambas para o aprendizado lexical (SCHMITT, 2008).

${ }^{5}$ Esperava-se que o grupo que recebeu a intervenção didática pudesse recuperar os itens lexicais sob testagem mais facilmente. 
dois grupos de informantes recebeu o processo de implementação, por um ano, e outra parte, por dois anos. Ambos os grupos foram comparados a grupos de controle semelhantes linguisticamente, os quais não receberam implementação lexical, para acompanhamento e contraste dos dados coletados. Como resultado, verificou-se que os alunos não nativos que participaram do processo de implementação lexical por mais tempo tiveram desenvolvimento bem superior aos demais. Também foi verificado que os alunos nativos, sob processo de implementação, tiveram um acréscimo significativo em seu vocabulário se comparados a outros alunos não nativos do grupo de controle.

A segunda pesquisa (SCHMITT; ZIMMERMAN, 2002) apresenta tanto dados relativos a uma pesquisa transversal realizada com alunos universitários e pós-graduandos não nativos de inglês, oriundos de países de diferentes línguas e com bons conhecimentos linguísticos da L2, quanto com alunos nativos de inglês, os quais frequentavam universidades estadunidenses ou britânicas. Todavia, os alunos não nativos de inglês apresentaram índices de dominância da derivação lexical de termos recorrentes na língua inglesa bem inferior aos dados coletados de falantes nativos em situação acadêmica semelhante. Como resultado, a pesquisa de Schmitt e Zimmerman (2002) demonstrou que mesmo falantes estrangeiros com muita competência comunicativa na L2 podem apresentar dados aquém dos índices alcançados por alunos nativos de faixa etária e escolarização semelhantes.

Assim, embora essas pesquisas utilizadas como referenciais metodológicos contassem com alunos imersos na L2 e com idades diferentes dos sujeitos deste estudo, a pesquisa de Mclaughlin, August e Snow (2.000) ofereceu suporte para o trabalho de implementação desenvolvido neste estudo, enquanto a pesquisa de Schmitt e Zimmerman (2002) ofereceu referencial metodológico para os testes desenvolvidos nas três etapas desta pesquisa.

\section{Afinal, QUanto Vocabulário É NECESSÁRIo PaRa a COMUNiCAÇão?}

O Projeto Curricular Nacional ${ }^{6}$ (PCN) para Linguagens, Códigos e suas Tecnologias, do Ministério da Educação e Cultura (MEC) prevê um processo de letramento ${ }^{7}$ (SOARES, 2020) do aluno no Ensino Médio, pois defende que o foco da aprendizagem deve "centrar-se na função comunicativa por excelência, visando prioritariamente à leitura e à compreensão de textos verbais orais e escritos - portanto, a comunicação em diferentes situações da vida cotidiana" (MEC, 2000, p. 94). Todavia, não tem havido pesquisas sobre o aprendizado de línguas estrangeiras em escolas regulares (PAIVA, 2012), assim como a linguística aplicada não tem dedicado

\footnotetext{
${ }^{6}$ Não foi utilizada a Base Nacional Comum Curricular (BNCC), pois o novo documento, em 2018 (ano desta pesquisa), ainda estava sendo "adaptado" para sua implantação estadual.

${ }^{7}$ De acordo com Soares (2020), a alfabetização envolve "aprender o sistema de escrita alfabética", fornece insumos para "ler e escrever textos". Já os "usos da escrita", que envolvem o contexto sociocultural, a questão de gêneros textuais e a linguística do texto e relacionados aos "contextos sociais e culturais de usos da escrita", fazem referência ao processo de letramento, ou seja, o uso competente da leitura e da escrita em práticas sociais.
} 
espaço significativo para a aprendizagem de léxico em língua estrangeira (L2) na atualidade, de acordo com Carter e Mccarthy (2014), embora o vocabulário seja fundamental tanto para o desenvolvimento de leitura e escrita quanto para as interações orais em L2.

Assim, o trabalho desenvolvido em sala de aula visa o vocabulário geral e específico para que as informações contidas em diferentes gêneros textuais sejam decodificadas e interpretadas, em um primeiro momento, e mais tarde sejam produzidas. Com relação a esse trabalho com o léxico em L2:

A tradição, tanto no ensino de línguas estrangeiras como da língua materna, tem destacado a importância do vocabulário através de inúmeras atividades pedagógicas, desde as listas de palavras descontextualizadas a serem decoradas pelos aprendizes até atividades mais significativas como jogos do tipo forca, bingo, caça-palavra, memória, palavras cruzadas, etc. (LEFFA, 2000, p. 17).

Embora seja reconhecida essa importância do vocabulário para aprendizagem de L2, mesmo entre autores, não há unanimidade sobre a quantidade necessária de vocabulário para comunicação eficiente, tampouco qual é a quantidade de exposição necessária para que um novo item lexical faça parte do repertório de reconhecimento do aprendiz.

Schmitt (2008) ressalva a importância tanto do conhecimento de um volume grande de palavras quanto de seu conhecimento em profundidade, ou seja, o autor ressalta a importância do conhecimento qualitativo, em diferentes contextos, do uso do léxico, inclusive com relação às palavras de mesma base lexical. Além disso, Schmitt (2014) defende que na língua inglesa há palavras muito recorrentes, ou palavras de alta frequência. Desse modo, quando os aprendizes passam a conhecer esses termos, as atividades de leitura e compreensão tanto de textos orais quanto escritos podem tornar-se mais eficazes (SCHMITT; MCCARTHY, 1997).

Autores como Zahar, Cobb e Spada (2001) sugerem que, para alunos de níveis mais avançados, considerados sujeitos com maior facilidade para aprendizagem (SCHMITT, 2008), seriam necessários de oito a dez encontros com determinada palavra para que esta seja apreendida. Porém, Pigada e Schmitt (2006) constataram que, mesmo após mais de vinte exposições a determinado termo, algumas palavras pareciam difíceis de ser apreendidas por alguns alunos.

Entretanto, Nation e Meara (2014) consideram que a quantidade de vocabulário limita os tipos de texto que um falante consegue ler L2 com bom desempenho. Desse modo, para comunicação efetiva na língua-alvo, Schmitt (2008) sugere de 8 mil a 9 mil famílias de palavras ${ }^{8}$ para a leitura e de 5 mil a 7 mil famílias de palavras para a compreensão na língua oral. Muito embora pesquisas demonstrem que, na oralidade, 2 mil a 3 mil famílias de palavras sejam

\footnotetext{
${ }^{8}$ Autores, tais como Schmitt (2008) e Nation (2006), consideram "famílias de palavras" os itens lexicais com a mesma raiz para indexicação lexical (substantivos, adjetivos etc.).
} 
requeridas para a compreensão oral de $95 \%$ ou de 6 mil a 7 mil famílias de palavras para uma compreensão efetiva de 98\% (SCHMITT, 2008).

Nation (2006) também defende serem necessárias de 8 mil a 9 mil famílias de palavras para uma compreensão efetiva de $98 \%$ do vocabulário presente em textos autênticos de diferentes gêneros textuais com base no British National Corpus ${ }^{9}$ (BNC). Para esse autor, falantes nativos com formação acadêmica e com mais de vinte anos de idade podem reconhecer cerca de 20 mil famílias de palavras, excluindo-se nomes próprios e formas derivadas transparentes. Ainda, falantes não nativos escolarizados (com formação universitária) em nível avançado de aprendizagem de inglês possivelmente reconheçam cerca de 8 mil a 9 mil famílias de palavras (NATION, 2006).

De acordo com Nation $(2006,2014)$, com $80 \%$ de compreensão lexical (20 palavras desconhecidas a cada 100), a compreensão na língua-alvo não é adequada, pois, com uma cobertura lexical de $90 \%$, poucos conseguem uma compreensão adequada do texto. Com $95 \%$ de compreensão lexical (uma palavra desconhecida em 20) alguns já apresentam compreensão mais adequada. Porém, com $98 \%$ de cobertura lexical (uma palavra desconhecida em 50 ), a maioria dos falantes obtém uma compreensão adequada do texto (NATION, 2006, 2014).

Ainda sobre a quantidade de vocabulário para comunicação eficiente, Schmitt e Schmitt (2020) postulam que essa relação depende da situação de comunicação, pois na audição (listening) as pessoas precisam entender a linguagem que as envolve, enquanto na oralidade podem ajustar a linguagem ao seu nível de proficiência. Schmitt (2008) também ressalta que a falha na aprendizagem de vocabulário faz com que a mera exposição ao léxico seja vista como não relevante para seu aprendizado. Em consonância, Peter e Webb (2018) defendem que a aprendizagem de novos itens lexicais pode tornar-se mais fácil se já houver conhecimento básico prévio da língua.

Indubitavelmente, quanto mais vocabulário conhecido pelo sujeito, maiores as chances de êxito na depreensão de ideias e conceitos presentes em um texto, seja este em L1 ou em L2. Assim, como veremos nos dados coletados, o conhecimento lexical dos alunos pesquisados, abaixo dos 50\%, de fato inviabiliza a leitura e compreensão adequada de diferentes gêneros textuais em sala de aula, o que corrobora a importância de pesquisas na área de aquisição lexical.

\section{A pesquisa Realizada}

No início da aplicação deste estudo, houve uma explicação sucinta para as turmas acompanhadas sobre a pesquisa a ser desenvolvida pela professora pesquisadora, assim como lhes

9 Disponível em: http://ucrel.lancs.ac.uk/bncfreq/lists/5_1_all_rank_noun.txt; http://ucrel.lancs.ac.uk/bncfreq/lists/5_2_all_rank_verb.txt; http://ucrel.lancs.ac.uk/bncfreq/lists/5_3_all_rank_adjective.txt. Acesso em: 5 nov.17. 
foi assegurado que todos os dados reais, espontâneos e individuais, coletados nos testes, seriam úteis para que a professora pudesse direcionar suas aulas para um melhor aproveitamento por parte dos estudantes, sem haver a geração de notas com base nas respostas dadas. Desse modo, foram invalidados os dados de alunos que não demonstraram interesse ao responder a pesquisa e/ou ética.

\section{O PÚBLICO-ALVO DESTA PESQUISA}

O público-alvo desta pesquisa foi composto inicialmente por 44 alunos ingressos no Ensino Médio de um colégio estadual da região de Curitiba, com idades entre 14 e 16 anos no período da pesquisa, dos quais 21 alunos eram do grupo de intervenção (G - I) e os outros 23 alunos eram do grupo de controle $(\mathrm{G}-\mathrm{C})$.

Entretanto, apenas oito alunos do G - I participaram das três etapas da pesquisa. Quanto ao G-C, 13 alunos participaram das três etapas da coleta dos dados, mas apenas 11 destes puderam ter seus dados analisados nesta pesquisa de campo, pois dois alunos consultaram o celular para a resolução dos testes, o que invalidou a veracidade de seus dados.

Dos 19 alunos participantes de todas as fases da pesquisa, nove destes eram meninas e dez eram meninos, com perfis bem distintos, tanto em relação ao interesse pelo estudo de L2, quanto ao compromisso com o próprio desempenho acadêmico. Todavia, tais fatores não demonstraram impacto relevante para os dados gerais, não sendo apresentados aqui pelo recorte epistemológico deste artigo.

Ambas as turmas foram receptivas e solícitas para a realização dos testes em suas três fases, as quais contaram com a participação de alguns alunos que declaravam não serem simpatizantes da língua inglesa em aulas anteriores à pesquisa, mas que tentaram realizar as atividades com visível dedicação.

\section{As TRÊS FASES DO TESTE: INSTRUMENTOS E OBJETIVOS}

No início desta pesquisa, na fase 1 , houve a aplicação de dois testes. O primeiro instrumento de pesquisa foi um questionário sociocultural, o qual abrangeu dados familiares, de acesso a bens simbólicos (STEINER, 2016), tais como internet e tv a cabo, além da motivação e gosto por aprender inglês, com a intenção de tentar averiguar possíveis fatores extrínsecos e intrínsecos determinantes para o (não) aprendizado da língua inglesa como L2, além de permitir tanto a compilação de dados com relação aos informantes, quanto servir como linha-mestra para a pesquisa a ser desenvolvida. Ademais, também houve intuito de balizar a escolha dos demais instrumentos de pesquisa (DÖRNYEI, 2003). 
O segundo instrumento utilizado na fase 1 foi uma lista com 100 palavras consideradas muito recorrentes na língua inglesa, de acordo com os bancos de dados linguísticos do Cambridge and Nottingham Corpus of Discourse in English (CANCODE) $)^{10} \mathrm{e}$ British National Corpus (BNC), as quais deveriam ser traduzidas para o português. Tais vocábulos foram analisados sob a perspectiva de alunos em processo de alfabetização na língua estrangeira, ou seja, foram considerados mesmo os itens com desvios de ortografia, desde que a palavra alvo fosse compreendida, pois denotariam vocábulos em processo de aquisição. Por motivo similar, também receberam pontuação positiva tanto termos conjugados quanto no infinitivo, assim como foi aceito o significado aproximado em relação ao significado vernáculo.

A proporção das palavras componentes desse teste da fase 1 foi de 50 substantivos, ${ }^{11} 30$ verbos $^{12}$ e 20 adjetivos ${ }^{13}$ visando a representar, de modo geral, a distribuição dos itens lexicais na língua inglesa escrita (NATION, 2001). Além disso, houve o trabalho com duas palavras pertencentes a duas classes diferentes (work/sustantivo, work/verbo, other/adjetivo, other/advérbio). Mesmo assim, durante os testes, poucos perceberam a presença de dois vocábulos ortograficamente semelhantes, mas dentro de grupos/classes gramaticais diferentes. Além disso, conforme observado por Schmitt (2008), os itens lexicais pertencentes à classe adverbial, de fato, foram as palavras menos conhecidas pelo grupo. Entretanto, não foi exigido o conhecimento explícito sobre tais classes gramaticais durante as fases desta pesquisa.

$\mathrm{Na}$ fase 2, o instrumento de pesquisa utilizado foi uma atividade tanto para preenchimento de lacunas com as palavras sob testagem em inglês quanto de tradução de vocábulos previamente sublinhados em sentenças simples, as quais permitiam a contextualização do vocábulo em língua inglesa, diferentemente do realizado na fase 1, para não limitar o aprendizado do estudante a apenas algumas informações sobre a forma e seu significado, tampouco limitar a relação entre estes (SCHMITT, 2014).

Para essa segunda fase, foram selecionadas 29 palavras $^{14}$ menos reconhecidas da lista inicial de 100 palavras da fase 1 pelos sujeitos participantes, sendo algumas destas bem recorrentes em materiais didáticos, já outras com baixa ocorrência (re)conhecidas pela maioria dos estudantes pesquisados..$^{15}$ Assim, o "ineditismo" de tais itens lexicais poderia proporcionar a verificação do aprendizado de palavras realmente "novas" para os aprendizes, além

\footnotetext{
${ }^{10}$ Disponível em: https://www.cancode.us.

${ }^{11}$ Time/ year/people/way/man/ day/thing/ child/Mr./ work/ life/ woman/government/case/ number/world/ house/ area/ place/ hand/ party/school/ country/ point/ week/ member/ end/ state/ word/ fact/ head/ month/ side/ business/night/ eye/ home/ power/ change/ percent/development/money/ book/ water/ other/ room/level/ council/ policy/market.

${ }^{12} \mathrm{Be} /$ have/do/ will/say/would/can/get/ make/go/see/know/take/could/ think/come/give/look/may/should/ find/want/ tell/ must/ put/ mean/ become/ leave/work/ need.

${ }^{13} \mathrm{Other} /$ good/ new/ old/ great/ high/small/different/large/ young/British/right/ early/possible/ big/little/ able/ late/ general/ full. ${ }^{14} \mathrm{~A}$ fase 2 contou com 32 palavras, estando 30 destas presentes na Fase 1. Além disso, 2 palavras - often e always - foram inseridas para testar a manutenção na memória recente de advérbios estudados antes da implementação lexical.

${ }^{15}$ Com base em observação empírica da pesquisadora em escolas regulares, tanto da rede pública quanto da rede particular de ensino.
} 
de proporcionar à pesquisadora a validação do processo de implementação lexical para o reconhecimento desses itens lexicais após algumas exposições (WARING; TAKAKI, 2003).

Os vocábulos police, always, often foram acrescentados uma vez que policy, pela ortografia semelhante, foi bastante confundido com police na fase 1, enquanto os termos always e often foram vocábulos vistos como conteúdo didático dois meses antes da aplicação desse teste. Assim, a expectativa era que possibilitassem uma pequena amostra da retenção de conteúdo visto em sala, no período anterior às atividades didáticas complementares.

$\mathrm{Na}$ fase 3 , o instrumento de pesquisa utilizado foi uma lista de palavras para reconhecimento pós-atividades de fixação lexical. Nessa etapa, foi requerido aos alunos participantes desta pesquisa que traduzissem para o português as 38 palavras ${ }^{16}$ também presentes na fase 2 , por apresentarem baixo índice de reconhecimento na lista das 100 palavras da fase 1.

\section{ATIVIDADES DIDÁTICAS UTILIZADAS NA IMPLEMENTAÇÃo DE VOCABULÁRIO}

Com vistas a garantir maior exposição ao vocabulário, dentre as atividades realizadas, houve o trabalho com quatro atividades muito presentes nos materiais didáticos (VERONEZI, 2003, 2019), descritas brevemente a seguir:

(1) Leitura de textos autênticos (Reading): habilidade mais relacionada à aquisição lexical, pois oferece amostras da língua em uma rede de estruturas tanto semântica quanto pragmática (PARIBAKHT; WESCHE, 1997). Assim, o texto permite o trabalho com o todo, apresentando o vocabulário em contexto, ampliando o conhecimento das estruturas sintáticas e conduzindo à apuração da habilidade de interpretação textual em outra língua, além da ampliação do léxico em contexto (ZAHAR; COBB; SPADA, 2001).

(2) Questionário (Answering the Questions): atividade muito utilizada como exercício após o trabalho com textos, gráficos e/ou gravuras, pois permite ao aprendiz fazer uma leitura atomística do "objeto-alvo". Nessa atividade, o aprendiz realiza um trabalho constante de "ida e vinda" ao objeto do questionário para criar, fundamentar e confirmar sua resposta $(O$ Q). Quando realizada na língua-alvo, essa atividade possibilita a sistematização de estruturas sintáticas pelo aprendiz, ao revisar e descobrir elementos gramaticais da língua. Também possibilita a reelaboração de conceitos linguísticos, além de propiciar a autocorreção do aprendiz (PARIBAKHT; WESCHE, 1997).

\footnotetext{
${ }^{16}$ Houve um aumento de 32 palavras, na Fase 2, para 38 palavras, na Fase 3, devido ao fato de a pesquisadora incluir palavras bem recorrentes na língua inglesa e nas atividades em sala e querer testar oficialmente o reconhecimento destas pelos alunos pesquisados. Os vocábulos "livro", "ver", "ótimo", e "atrasado" constavam na Fase 1 e foram analisados apenas na Fase 3. Os vocábulos "dinheiro", "casa" e "britânico" estavam entre o conteúdo das sentenças, mas não foi requerida sua tradução. Além disso, foi inserido mais um verbo "fazer" para induzir os alunos a perceberem a existência de dois verbos "fazer" no inglês. Também foram retirados os advérbios "often/frequentemente", e "always/sempre", os quais não constavam na Fase 1, mas foram inseridos na Fase 2 para verificar a permanência na memória recente de termos vistos antes do início da pesquisa.
} 
(3) Preenchimento de Lacunas (Filling Gaps): atividade útil tanto para medir a capacidade de recuperação do vocabulário estudado quanto para fixação de itens lexicais, foi utilizada também durante os exercícios de sala e também no teste da fase 2 , pois com essa atividade o professor pode verificar o grau de recuperação de determinado vocábulo em contexto específico, reapresentado ao aprendiz ao longo de várias aulas (SCHMITT, 2008).

(4) Tradução (Translation): exercício de linguagem que mais utiliza a análise contrastiva da linguagem (ELLIS, 1994), pois todo o trabalho baseia-se na correspondência entre as formas linguísticas de L1 e L2, onde a L2 pode ser considerada como ponto de partida (L2 $\rightarrow$ L1) ou ponto de chegada ( $\mathrm{L} 1 \rightarrow \mathrm{L} 2)$. Assim, o foco do aprendiz mantém-se na transferência da estrutura de Li para L2, sendo assim necessário o uso de dicionários bilíngues, não apenas para o estágio inicial, por este proporcionar ao aprendiz maior confiança no contato inicial com a "nova" língua, visto como fundamental no processo de aprendizagem (SCHMITT, 2008), mas também para alunos do nível intermediário.

Isso porque estudos também confirmam a importância do uso da tradução dentro e fora da sala de aula (AUGUSTYN, 2013), uma vez que o aprendiz nem sempre consegue inferir corretamente a palavra desconhecida (SCHMITT, 2008). Ademais, Schmitt (2014) considera que os dicionários monolíngues podem não ser eficazes para clarificar todos os conceitos pela complexidade dos vocábulos utilizados em suas definições (SCHMITT; SCHMITT, 2014).

\section{ANÁliSE DOS DADOS SOBRE A RELAÇÃo ENTRE IDADE E MAIOR APRENDIZAGEM LEXICAL DE L2}

Embora muito autores defendam a Hipótese do Período Crítico ${ }^{17}$ (BLOCK, 2003), a qual relaciona a melhor aprendizagem de uma L2 até a adolescência (BLOCK, 2003), com relação à variante idade, não foi possível associar o desempenho dos alunos pesquisados ao seu desenvolvimento cronológico ao término das três fases.

\section{GRUPO DE INTERVENÇão}

Dos oito indivíduos que participaram de todas as fases desta pesquisa, todos estavam na faixa etária entre 14 e 16 anos no período de aplicação dos testes. Dos alunos com maior pontuação, dois destes estavam com 14 anos e 10 meses ( $\mathrm{I}-1$ e I - 3), um destes estava com 15

\footnotetext{
${ }^{17}$ Tradicionalmente, a hipótese do período crítico (BLOCK, 2003) aplica-se à aquisição de Língua Materna, de modo que há uma predisposição biológica para aquisição espontânea de primeira(s) língua(s), mediante exposição ao input linguístico, até a média dos sete anos. Contudo, embora alguns trabalhos expandam a perspectiva para LE/L2, muitos estudos, sobretudo em Linguística Aplicada, sob viés Interacionista, mostram que a hipótese do período crítico não se aplica a esses casos.
} 
UM ESTUDO DE CASO SOBRE A IMPORTÂNCIA DAS VARIÁVEIS "GÊNERO" E "IDADE” NA APRENDIZAGEM DE L2 NO ENSINO MÉDIO

anos e 5 meses ( $\mathrm{I}$ - 6) e outro estava com 16 anos e 6 meses no momento da aplicação da fase $3(\mathrm{I}-8)$, conforme pode ser visto na tabela a seguir:

Tabela 1 - Comparação de desempenho x idade (G - I)

\begin{tabular}{c|c|c|c|c|c}
\hline Aluno(a) & Idade & Fase 1 & Fase 2 & Fase 3 & Desempenho nas 3 Fases (\%) \\
\hline $\mathrm{I}-1$ & $14 a 10 \mathrm{~m}$ & $32 / 100$ & $19 / 32$ & $25 / 38$ & $32 / 50 / 66$ \\
\hline $\mathrm{I}-2$ & $15 \mathrm{a10m}$ & $22 / 100$ & $8 / 32$ & $5 / 38$ & $22 / 31 / 13$ \\
\hline $\mathrm{I}-3$ & $14 a 10 \mathrm{~m}$ & $21 / 100$ & $12 / 32$ & $10 / 38$ & $21 / 32 / 26$ \\
\hline $\mathrm{I}-4$ & $13 \mathrm{a} 1 \mathrm{~m}$ & $44 / 100$ & $2 / 32$ & $2 / 38$ & $44 / 5 / 5$ \\
\hline $\mathrm{I}-5$ & $15 \mathrm{alm}$ & $7 / 100$ & $6 / 32$ & $8 / 38$ & $7 / 16 / 21$ \\
\hline $\mathrm{I}-6$ & $15 \mathrm{a} 5 \mathrm{~m}$ & $46 / 100$ & $9 / 32$ & $14 / 38$ & $46 / 24 / 37$ \\
\hline $\mathrm{I}-7$ & $16 a 11 \mathrm{~m}$ & $27 / 100$ & $4 / 32$ & $7 / 38$ & $27 / 10 / 18$ \\
\hline $\mathrm{I}-8$ & $16 a 6 \mathrm{~m}$ & $43 / 100$ & $13 / 32$ & $27 / 38$ & $43 / 34 / 71$ \\
\hline
\end{tabular}

Fonte: Veronezi (2019)

Após análise da tabela 1, é possível verificar que não há relação clara entre as faixas etárias (13 anos, 14 anos, 15 anos e 16 anos) e o desempenho nos testes, pois I - 8, de 16 anos e 6 meses, que apresentou o melhor desempenho na fase 3, teve somente dois acertos acima do desempenho de I-1, I ano e 8 meses mais jovem, cujo desempenho, aliás, foi melhor do que o desempenho de I - 8 na fase 2. Por sua vez, I-3, com a mesma idade de I-1, ambos com 14 anos e 10 meses, apresentou o quarto melhor resultado na Fase 2, mas com índice maior do que I -6 , sete meses mais velho, com 15 anos e 5 meses, e apenas um ponto abaixo de I - 8, I ano e 8 meses mais velho, com 16 anos e 6 meses.

Em uma leitura percentual, os dados mostram um crescimento nos resultados dos testes de apenas dois alunos, I-1, com 14 anos e 10 meses, e I - 5, com 15 anos e 1 mês. Ainda, de acordo com os dados coletados, os alunos I-3, 14 anos e 10 meses, e I-8, 16 anos e 6 meses, tiveram queda em seus índices na fase 2 , mas na fase 3 superaram seus índices da fase 1. Já os dados de I - 6, com 15 anos e 5 meses, e I - 7, com 16 anos e 11 meses, os quais apresentaram declínio em seus índices na fase 2 em comparação com seus dados da fase 1 , mostraram uma recuperação superior a 50\% em seus índices da fase 3, embora ainda inferiores a seus índices de partida.

\section{GRUPO DE CONTROLE}

Com relação ao grupo de controle, os dados coletados nos testes das três fases demonstraram que os três maiores índices são dos alunos $C-1, C-5$ e C - 11, os quais têm ótima base 
no inglês e, por conseguinte, se destacaram com relação ao grupo durante a realização de exercícios, necessitando de menos apoio durante a realização de atividades.

A tabela 2, a seguir, discrimina a idade e o desempenho de cada participante do grupo de controle ao longo das 3 fases desta pesquisa:

Tabela 2 - Comparação de desempenho x idade (G - C)

\begin{tabular}{c|c|c|c|c|c}
\hline Aluno(a) & Idade & Fase 1 & Fase 2 & Fase 3 & Desempenho nas 3 Fases (\%) \\
\hline C - 1 & $14 a 10 m$ & $69 / 100$ & $28 / 32$ & $32 / 38$ & $69 / 84 / 84$ \\
\hline C - 2 & $16 a$ & $22 / 100$ & $1 / 32$ & $9 / 38$ & $22 / 3 / 24$ \\
\hline$C-3$ & $16 a$ & $10 / 100$ & $1 / 32$ & $1 / 38$ & $10 / 3 / 3$ \\
\hline$C-4$ & $15 a$ & $20 / 100$ & $10 / 32$ & $9 / 38$ & $20 / 26 / 24$ \\
\hline$C-5$ & $15 a 5 m$ & $97 / 100$ & $28 / 32$ & $37 / 38$ & $97 / 74 / 97$ \\
\hline$C-6$ & $15 a 6 m$ & $16 / 100$ & $11 / 32$ & $7 / 38$ & $16 / 29 / 18$ \\
\hline$C-7$ & $16 a 11 m$ & $36 / 100$ & $7 / 32$ & $15 / 38$ & $36 / 18 / 39$ \\
\hline$C-8$ & $15 a 5 m$ & $9 / 100$ & $7 / 32$ & $5 / 38$ & $9 / 18 / 13$ \\
\hline$C-9$ & $16 a 7 m$ & $9 / 100$ & $4 / 32$ & $4 / 38$ & $9 / 10 / 11$ \\
\hline$C-10$ & $15 a 2 m$ & $15 / 100$ & $11 / 32$ & $13 / 38$ & $15 / 29 / 34$ \\
\hline$C-11$ & $14 a 9 m$ & $91 / 100$ & $30 / 32$ & $33 / 38$ & $91 / 79 / 87$ \\
\hline
\end{tabular}

Fonte: Veronezi (2019)

Assim, de acordo com a Tabela 2, a exemplo dos dados do grupo de intervenção, não foi possível estabelecer um paralelo entre a variante idade e o grau de aprendizagem da língua inglesa. Entre os três alunos que se destacaram no grupo por terem bons conhecimentos no idioma, $\mathrm{C}-1$ e C - 11 têm um mês de diferença na idade (14 anos e 10 meses e 14 anos e 9 meses na terceira fase dos testes, respectivamente). $C-5$, que obteve a melhor pontuação dos três alunos na média, era poucos meses mais velho do que esses dois colegas, tendo 15 anos e 5 meses.

Com relação aos dados de $\mathrm{C}-2$, mesmo este tendo dificuldade de aprendizagem, é possível verificar que o desempenho de $\mathrm{C}-2$ na fase 3 foi superior a outros alunos da turma. Os dados ainda mostraram que $\mathrm{C}-2$ e $\mathrm{C}-7$ tiveram sensível diminuição nos índices da fase 2 , mas na fase 3 pontuaram bem e superaram seus índices da fase 1. Já C - 3 apresentou baixo aproveitamento em todas as fases da pesquisa, obtendo o mesmo índice nas fases 2 e 3.

Em análise percentual, os dados revelam que $\mathrm{C}-10$ foi a única pesquisada que apresentou crescimento contínuo nas três fases da pesquisa. Contrariamente ao esperado, $\mathrm{C}-1, \mathrm{C}-5$ e C - 11, os melhores alunos da turma em rendimento, não apresentaram o índice de $100 \%$ em nenhuma das fases, mesmo com desempenhos muito acima da média da turma. 
Porém, com relação a $C-4, C-6$ e $C-8$, a tabela mostra um significativo aumento em pontuação na fase 2 , mas há queda nessa pontuação na fase 3 . Todavia, tal pontuação ainda foi superior aos índices da fase 1. Já C - 9, o segundo pior índice do grupo de controle, apresentou melhora quase imperceptível entre a primeira fase e as duas posteriores. Desse modo, o aluno, embora já repetente na série, não se mostrou beneficiado pelo processo de complementação lexical.

\section{ANÁLISE DOS DADOS SOBRE A RELAÇÃO ENTRE GÊNERO E MAIOR APRENDIZAGEM LEXICAL DE L2}

Em seu texto de 2007, Bernat e Lloyd citam a crescente preocupação de pesquisadores a respeito das crenças sobre aprendizagem de línguas e sua relação com diferenças individuais, tais como a questão do gênero. Nesta pesquisa, coincidentemente houve equilíbrio entre o número de informantes que eram do gênero masculino e do gênero feminino. Assim, dos 19 pesquisados que participaram da pesquisa, nove eram meninas e dez eram meninos.

\section{GRUPO DE INTERVENÇÃo}

No grupo de intervenção, houve equilíbrio entre o número de participantes do gênero feminino e do gênero masculino, pois houve quatro participantes de cada gênero, conforme apresentado na tabela abaixo:

Tabela 3 - Comparação de gênero x desempenho nas 3 fases (G - I)

\begin{tabular}{c|c|c|c}
\hline Meninas & $\begin{array}{c}\text { Desempenho percentual nas 3 } \\
\text { fases (\%) }\end{array}$ & Meninos & $\begin{array}{c}\text { Desempenho percentual nas 3 } \\
\text { fases (\%) }\end{array}$ \\
\hline $\mathrm{I}-1$ & $32 / 50 / 66$ & $\mathrm{I}-2$ & $22 / 31 / 13$ \\
\hline $\mathrm{I}-4$ & $44 / 5 / 5$ & $\mathrm{I}-3$ & $21 / 32 / 26$ \\
\hline $\mathrm{I}-5$ & $7 / 16 / 21$ & $\mathrm{I}-6$ & $46 / 24 / 37$ \\
\hline $\mathrm{I}-8$ & $43 / 34 / 71$ & $\mathrm{I}-7$ & $27 / 10 / 18$ \\
\hline
\end{tabular}

Fonte: Veronezi (2019)

$\mathrm{Na}$ tabela 3, é possível verificar que duas das participantes obtiveram destaque: I - I teve o melhor desempenho de toda a turma com resultado ascendente da fase 1 para a fase 3 , enquanto I -8 teve o segundo melhor índice de desempenho da turma, pois oscilou negativamente entre a fase $1 \mathrm{e}$ a fase 2 . Entretanto, as outras duas participantes meninas tiveram um desempenho muito baixo, mas, I -5 apresentou um crescimento contínuo ao longo das três fases. Quanto à participante I-4, é possível verificar que na fase I teve desempenho de $44 \%$ de 
acerto, enquanto nas fases 2 e 3 teve desempenho inferior a $15 \%$, mostrando que o trabalho de implementação lexical, em termos estatísticos, não impactou significativamente essa aprendiz.

Com relação aos participantes do gênero masculino, nenhum dos pesquisados demonstrou um crescimento contínuo ao longo das 3 fases. No grupo dos meninos, I - 6 teve o melhor resultado entre os meninos e o terceiro melhor resultado da turma, enquanto I - 2, I - 3 e I - 7 tiveram desempenhos consideravelmente oscilantes ao longo das três fases. Notadamente, o desempenho desses alunos nas fases 2 e 3 não demonstram ganho lexical em relação às palavras-alvo sob testagem.

\section{GRUPo DE CONTROLE}

No grupo de controle, a divisão dos alunos de acordo com o gênero também ficou coincidentemente próxima: cinco dos informantes eram do gênero feminino e seis informantes eram do gênero masculino. Na tabela a seguir vemos os dados relativos a cada grupo.

Tabela 4 - Comparação de gênero x desempenho nas 3 fases $(G-C)$

\begin{tabular}{c|c|c|c}
\hline Meninas & $\begin{array}{c}\text { Desempenho percentual nas 3 } \\
\text { Fases (\%) }\end{array}$ & Meninos & $\begin{array}{c}\text { Desempenho percentual nas 3 } \\
\text { Fases (\%) }\end{array}$ \\
\hline $\mathrm{C}-1$ & $69 / 84 / 84$ & $\mathrm{C}-2$ & $22 / 3 / 24$ \\
\hline $\mathrm{C}-4$ & $20 / 26 / 24$ & $\mathrm{C}-3$ & $10 / 3 / 3$ \\
\hline $\mathrm{C}-6$ & $16 / 29 / 18$ & $\mathrm{C}-5$ & $97 / 74 / 97$ \\
\hline $\mathrm{C}-8$ & $9 / 18 / 13$ & $\mathrm{C}-7$ & $36 / 18 / 39$ \\
\hline $\mathrm{C}-10$ & $15 / 29 / 34$ & $\mathrm{C}-9$ & $9 / 10 / 11$ \\
\hline & & $\mathrm{C}-11$ & $91 / 79 / 87$ \\
\hline
\end{tabular}

Fonte: Veronezi (2019)

Na tabela 4, é possível verificar que no grupo do gênero feminino os resultados oscilaram ao longo das três fases, pois $\mathrm{C}-1$ teve desempenho acima da média, mas seus índices se mantiveram estáveis na segunda e terceira fases. Já C - 4, C - 6 e C - 8 tiveram desempenho melhor na fase 2 do que nas demais fases. Por sua vez, $\mathrm{C}-8$ teve o pior desempenho no grupo das meninas, mas esse não foi o pior da turma. Com relação à C-10, esta foi a única menina que teve desempenho progressivo nas 3 fases, embora seus índices sejam muito menores do que os de $\mathrm{C}-1$.

Com relação ao grupo dos meninos, $\mathrm{C}-5$ e C - 11 tiveram os melhores desempenhos do grupo de controle, embora seus desempenhos não tenham sido progressivos ao longo das três fases. Ainda, C - 7 teve o terceiro melhor desempenho da turma, enquanto $\mathrm{C}-2$ teve um desempenho ruim na fase 2. Entretanto, o desempenho de $\mathrm{C}-2$ foi melhor do que o desempenho 
do menino $\mathrm{C}-9$. Quanto ao desempenho de $\mathrm{C}-3$, de acordo com os dados coletados e com seu desempenho em sala de aula, este não foi impactado pelas atividades de complementação lexical realizadas ao longo do período da pesquisa, pois seus índices permaneceram baixos e inalterados entre as fases 2 e 3 .

Assim, embora os dados obtidos nas três fases desta pesquisa sejam favoráveis ao grupo dos meninos, não é possível fazer correlação entre os fatores gênero e aprendizagem de L2, pois, como dito anteriormente, $\mathrm{C}-5$ e C - 11 são alunos que chegaram ao Ensino Médio com bom arcabouço na língua inglesa, quando comparados aos demais da turma, o que certamente contribuiu para seu desempenho.

Bernat e Lloyd (2007) também chegaram a conclusão semelhante, pois ao analisarem pesquisas referentes à relação entre gênero e aprendizagem de línguas constataram que não houve dados conclusivos nas pesquisas. Assim, outros estudos deveriam ser conduzidos para averiguar melhor essa possível correlação na aprendizagem de L2 (BERNAT; LLOYD, 2007).

\section{CoNSIDERAÇõEs FINAIS}

Esta pesquisa empírica trabalhou com um corpus limitado de participantes, tanto do gênero feminino quanto do gênero masculino, os quais foram acompanhados ao longo de três meses com o objetivo de testar a eficácia de atividades de implementação lexical em sala de aula como forma de aquisição de vocabulário por alunos do primeiro ano do Ensino Médio e verificar a relação entre os fatores idade, gênero e aprendizagem de L2.

Entretanto, como visto nos grupos dos alunos participantes deste estudo, não foi possível estabelecer uma relação clara entre os fatores investigados, dado o número reduzido de informantes e possivelmente a duração da presente pesquisa, pois o processo de implementação realizado por Mclaughlin, August e Snow (2000) e tido como um dos referenciais metodológicos para este estudo, contou com um corpus muito mais amplo de informantes e concluiu que os alunos que participaram por dois anos obtiveram melhores resultados do que aqueles que participaram por apenas um ano.

Mesmo com uma duração de apenas três meses, foi possível verificar que, após a implementação de vocabulário realizada, os elementos lexicais sob pesquisa e testagem de forma contextualizada foram assimilados parcialmente pelos aprendizes do grupo de intervenção do presente estudo. Desse modo, os dados coletados foram úteis para sinalizar a necessidade de maior número de investigação sobre a aprendizagem de léxico no ensino regular, tanto no Ensino Fundamental quanto no Ensino Médio, bem como a necessidade de estudos com grupos maiores de informantes para corroborar ou refutar os dados obtidos na pesquisa apresentada neste artigo. 


\section{REFERÊNCIAS}

AUGUSTYN, P. No dictionaries in the classroom: Translation equivalents and vocabulary acquisition. International Journal of Lexicography, v. 26, n. 3, p. 362-385, 2013.

BAUER, L.; NATION, P. Word Families. New Zealand: Victoria University of Wellington, 1993.

BERNAT, E.; LLOYD, R. Exploring the gender effect on EFL learners' beliefs about language learning. 2007. Australian Journal of Educational \& Developmental Psychology. v. 7, 2007, pp 79-91, Macquarie University.

BLOCK, D. What does the "A" in SLA stand for? In: BLOCK, D. The Social Turn in Second Language Acquisition. Washington, D.C.: Georgetown University Press, 2003.

BRASIL. Ministério da Educação. Base Nacional Comum Curricular. Brasília, 2018. Disponível em: basenacionalcomum.mec.gov.br/images/BNCC_EI_EF_110518_versaofinal_site.pdf. Acesso em: 17 mar. 2021.

CARTER, R.; MCCARTHY, M. Word lists and learning words: some foundations. In: CARTER, R.; MCCARTHY, M. Vocabulary and language teaching. Routledge, 2014.

DAL'IGNA, M. C. Desempenho escolar de meninos e meninas: há diferença? Educação em revista, p. 241-267, 2007.

DÖRNYEI, Z. Questionnaires in second language research: construction, administration, and processing. New Jersey, NY: Lawrence Erlbaum Associates, 2003.

ELLIS, N. Consciousness in second language learning: Psychological perspectives on the role of conscious processes in vocabulary acquisition. In: HULSTIJN, J.; SCHMIDT, R. (eds.). Consciousness in Second Language Learning. AILA Review, v. 11, p. 37-56, 1994.

Flege, J. E. A non-critical period for second-language learning. In: FLEGE, J. E. (ed.). A sound approach to language matters: In honor of Ocke-Schwen Bohn. Open access e-book at Aurhus University Library. Aurhus University, 2019.

HULSTIJN, J.; SCHMIDT, R. (eds.). Consciousness in Second Language Learning. AILA Review, v. 11, p. 37-56, 1994.

LEFFA, V. Aspectos externos e internos da aquisição lexical. In: LEFFA, V. J. (Org.). As palavras e Sua Companhia: o Léxico na Aprendizagem. v. 1, p. 15 - 44. Pelotas: Educat, 2000.

MCLAUGHLIN, B.;AUGUST, D.; SNOW, C. Vocabulary Knowledge and Reading Comprehension in English Language Learners. Final Performance Report. Educational Resources information Center (ERIC), 2000. 
UM ESTUDO DE CASO SOBRE A IMPORTÂNCIA DAS VARIÁVEIS “GÊNERO” E “IDADE” NA APRENDIZAGEM DE L2 NO ENSINO MÉDIO

MINISTÉRIO DA EDUCAÇÃO E CULTURA (MEC). Parâmetros Curriculares Nacionais Ensino Médio: 2000. Disponível em: http://portal.mec.gov.br/seb/arquivos/pdf/linguagens. Acesso em: 27 jun.18.

NATION, I. S. P. How large a vocabulary is needed for reading and listening? Canadian Modern Language Review, v. 63, n. 1, p. 59-82, 2006.

NATION, P. How much input do you need to learn the most frequent 9,000 words? Reading in a Foreign Language, University of Hawai'i, v. 26, n. 2, p. 1-16, 2014.

NATION, I. S. P. Learning vocabulary in another language. Cambridge, UK: Cambridge University Press, 2001.

NATION, P.; MEARA, P. Vocabulary. In: SCHMITT, Norbert (ed.). An Introduction to Applied Linguistics. Second Edition. Londres: Hodder Education, 2014.

PAIVA, V. L. M. de O. Ensino de língua Inglesa no Ensino Médio: teoria e prática. São Paulo: Edições SM, 2012.

PARIBAKHT, T. S., WESCHE, M. Vocabulary Enhancement Activities and Reading for Meaning in Second Language Vocabulary Acquisition. In: COADY, J.; HUCKIN, T. (eds.). Second Language Vocabulary Acquisition. Cambridge: Cambridge University Press, 1997.

PIGADA, M.; SCHMITT, N. Vocabulary acquisition from extensive reading: a case study. Reading in a Foreign Language, v. 18, n. 1, p. 1-28, 2006.

SCHMITT, N. Review article: Instructed second language vocabulary learning. Language Teaching Research, University of Nottingham, v. 12, n. 3, p. 329-363, 2008.

SCHMITT, N. Size and Depth of Vocabulary Knowledge: What the Research Shows. University of Nottingham, 2014.

SCHMITT, N.; MCCARTHY, M. (Ed.). Vocabulary: description, acquisition and pedagogy. United Kingdom: Cambridge University Press, 1997.

SCHMITT, N.; SCHMITT, D. A reassessment of frequency and vocabulary size in L2 vocabulary teaching. Language Teaching, v. 47, n. 4, p. 484 -503, 2014.

SCHMITT, N.; SCHMITT, D. Vocabulary in language teaching. United Kingdom: Cambridge University Press, 2020.

SCHMITT, N.; ZIMMERMAN, C. Derivative Word Forms: What Do Learners Know? Tesol Quarterly, v. 36, n. 2, 2002.

SOARES, Magda. Alfaletrar: toda criança pode aprender a ler e a escrever. São Paulo: Contexto, 2020. 
STEINER, P. Altruísmo, dons e trocas Simbólicas: abordagens sociológicas da troca. Tradução de: PRADO, Raquel de Almeida; SALA, Lolita. Revisão de: JARDIM, Maria Chaves; ARTUR, Karen. São Paulo: Cultura Acadêmica, 2016.

VERONEZI, A. M. A Importância da Instrução Explícita no Processo de Ensino de Segunda Língua. 46 f. Monografia (Bacharelado em Língua Inglesa) - Setor de Ciências Humanas, Letras e Artes, Universidade Federal do Paraná, Curitiba, 2003.

VERONEZI, A. M. Estudo sobre aquisição de vocabulário no ensino médio através de intervenções didáticas em sala de aula. 145 f. Dissertação (Mestrado em Linguística Aplicada) - Setor de Ciências Humanas, Letras e Artes, Universidade Federal do Paraná, Curitiba, 2019.

WARING, R.; TAKAKI, M. At what rate do learners learn and retain new vocabulary from reading a graded reader? Reading in a Foreign Language, v. 15, p. 130-163, 2003.

ZAHAR, R.; COBB, T.; SPADA, N. Acquiring vocabulary through reading: Effects of frequency and contextual richness. The Canadian Modern Language Review, v. 57, n. 3, 541-572, 2001.

Recebido para publicação em: 28 jul. 2021. Aceito para publicação em: 4 nov. 2021. 